\title{
Planned Subject to Eye Chart Distance
}

National Cancer Institute

\section{Source}

National Cancer Institute. Planned Subject to Eye Chart Distance. NCI Thesaurus. Code C147476.

The planned distance between the subject and the eye chart during an eye assessment. 